\author{
Military Technical College \\ Kobry El-Kobbah, \\ Cairo, Egypt.
}

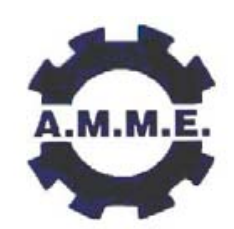

$13^{\text {th }}$ International Conference on Applied Mechanics and Mechanical Engineering.

\title{
COMPUTER MODELLING OF INDUCTION HEATING FOR THE PROCESSES OF SURFACE HARDENING
}

\author{
BEHULOVA M. ${ }^{*}$ and TARABA B. ${ }^{* *}$
}

\begin{abstract}
Processes of induction heating for surface hardening are mostly designed using engineering experience and a trial-and-error procedure. In connection with advance in computational technique and numerical methods, computer modelling and simulation are ever more exploited to support design and analysis of induction heat treatment processes. Induction heating represents a complex problem requiring to perform coupled electro-magnetic, thermal and static analyses. In the paper, the methodology of computer modelling and analysis of high-frequency induction heating processes using the program code ANSYS is discussed and applied for the numerical simulation of induction heating of a power cylinder piston.
\end{abstract}

\section{KEY WORDS}

Induction heating, Electro-magnetic fields, Temperature fields, Numerical simulation, FEM, Surface hardening

* Lecturer, Dpt. of Applied Mechanics, Inst. of Production Systems and Applied Mechanics, Faculty of Materials Science and Technology in Trnava, Slovak University of Technology in Bratislava, Slovak Republic

** Associate professor, Dpt. of Applied Mechanics, Inst. of Production Systems and Applied Mechanics, Faculty of Materials Science and Technology in Trnava, Slovak University of Technology in Bratislava, Slovak Republic 


\section{NOMENCLATURE}

\begin{tabular}{|c|c|c|}
\hline$A$ & {$\left[\mathrm{~Wb} \cdot \mathrm{m}^{-1}\right]$} & magnetic vector potential, \\
\hline B & {$[\mathrm{T}]$} & magnetic flux density, \\
\hline$C$ & {$\left[\mathrm{~J} \cdot \mathrm{kg}^{-1} \cdot \mathrm{K}^{-1}\right]$} & specific heat, \\
\hline$D$ & {$\left[\right.$ C. $\left.\mathrm{m}^{-2}\right]$} & vector of electric flux density, \\
\hline$E$ & {$\left[\mathrm{~V} \cdot \mathrm{m}^{-1}\right]$} & electric field intensity, \\
\hline$f$ & {$[\mathrm{~Hz}]$} & frequency of the source current, \\
\hline$H$ & {$\left[A \cdot \mathrm{m}^{-1}\right]$} & magnetic field intensity, \\
\hline$h$ & {$\left[\mathrm{~W} \cdot \mathrm{m}^{-2} \cdot \mathrm{K}^{-1}\right]$} & heat transfer coefficient, \\
\hline$h_{\mathrm{C}}$ & {$\left[\mathrm{W} \cdot \mathrm{m}^{-2} \cdot \mathrm{K}^{-1}\right]$} & convection heat transfer coefficient, \\
\hline$h_{\mathrm{R}}$ & {$\left[\mathrm{W} \cdot \mathrm{m}^{-2} \cdot \mathrm{K}^{-1}\right]$} & radiation heat transfer coefficient, \\
\hline$j$ & {$\left[\right.$ A. $\left.\mathrm{m}^{-2}\right]$} & current density, \\
\hline$q$ & {$\left[\mathrm{~W} \cdot \mathrm{m}^{-2}\right]$} & heat flux, \\
\hline$q_{v}$ & {$\left[\mathrm{~W} \cdot \mathrm{m}^{-3}\right]$} & volume heat source density, \\
\hline$T$ & {$[\mathrm{~K}]$} & temperature, \\
\hline$T_{\mathrm{w}}$ & {$[\mathrm{K}]$} & surface temperature, \\
\hline$T_{f}$ & {$[\mathrm{~K}]$} & fluid (surrounding) temperature, \\
\hline$t$ & [s] & time, \\
\hline $\mathbf{u}$ & {$[\mathrm{m}]$} & displacement vector, \\
\hline$\alpha_{v}$ & {$\left[\mathrm{~K}^{-1}\right]$} & linear coefficient of thermal expansion, \\
\hline$\delta$ & [m] & skin depth, \\
\hline$\varepsilon$ & {$\left[\mathrm{F} \cdot \mathrm{m}^{-1}\right]$} & permitivity, \\
\hline$\varepsilon_{12}$ & {$[-]$} & emissivity, \\
\hline$\lambda$ & {$\left[\mathrm{W} \cdot \mathrm{m}^{-1} \cdot \mathrm{K}^{-1}\right]$} & thermal conductivity, \\
\hline$\mu$ & {$\left[\mathrm{H} \cdot \mathrm{m}^{-1}\right]$} & magnetic permeability $\left(\mu=\mu_{0} \mu_{\mathrm{r}}\right)$. \\
\hline$\mu_{0}$ & {$\left[\mathrm{H} \cdot \mathrm{m}^{-1}\right]$} & permeability of vacuum $\left(\mu_{0}=4 \pi \cdot 10^{-7} \mathrm{H} \cdot \mathrm{m}^{-1}\right)$, \\
\hline$\mu_{\mathrm{r}}$ & {$[-]$} & relative permeability, \\
\hline$v$ & {$[-]$} & Poisson's ratio, \\
\hline$\rho$ & {$\left[\mathrm{kg} \cdot \mathrm{m}^{-3}\right]$} & density, \\
\hline$\rho_{\mathrm{e}}$ & [C. $\left.\mathrm{m}^{-3}\right]$ & free charge density, \\
\hline$\rho_{\mathrm{el}}$ & {$[\Omega . \mathrm{m}]$} & electrical resistance, \\
\hline$\sigma$ & [S.m] & electrical conductivity, \\
\hline$\omega$ & {$\left[\mathrm{s}^{-1}\right]$} & angular frequency. \\
\hline
\end{tabular}

\section{INTRODUCTION}

Induction heating is widely used in the industry. This heating method is applied with many benefits in melting, forming, in heat treatment of metals, in quenching, surface hardening, tempering and also in other processes. The main advantages of induction heating include very accurate control of heated surface and depth and high heating rates along with a relatively low energy consumption. From this point of view, the induction heating is especially suitable for automated processes.

In this paper, the methodology of numerical simulation of high-frequency induction heating by the program code ANSYS is presented. The process of induction heating for surface hardening of a power cylinder piston using two different induction coils are analysed. 


\section{PHYSICAL PRINCIPLE OF INDUCTION HEATING}

In induction heating process, an alternating current is passed through a conductor, mostly through a copper coil, creating an alternating magnetic field. In a part placed into this magnetic field, eddy currents are induced and material is heated up due to the resistive and hysteresis looses [1,2]. The induced current and consequently the generated heat are not uniformly distributed throughout the workpiece. Around $63 \%$ of induced current and $87 \%$ of generated heat is concentrated in the outer region called penetration or skin depth. The skin depth $\delta$ depends on electric and magnetic properties of material and mainly on the frequency of current in the induction coil. It can be calculated from the relationship [1]

$$
\delta=\sqrt{\frac{\rho_{\mathrm{el}}}{\pi \mu_{0} \mu_{\mathrm{r}} f}} .
$$

The fact that the heat is generated mostly in the thin surface layer is used preferably in the processes of surface quenching of magnetic materials. In these processes, the surface layer is heated very fast using the high-frequency inductor whereby the internal parts are practically unaffected. Rapid oil or water quenching results in the development of thin hardened surface layers.

\section{MATHEMATICAL MODEL}

The material behavior during induction heating is very complex. It involves coupled sets of partial differential equations, complicated boundary conditions for electro-magnetic, thermal and stress-strain fields and non-linear material properties [3-6]. In this reason, induction heating is necessary to solve as a coupled problem. The coupling between electro-magnetic and temperature fields is given by the dependence of electromagnetic properties on temperature and on the other hand the temperature field is influenced by the Joule heat generation. In addition, the magnetic permeability depends on the magnetic field density and thermal properties are temperature dependent. The boundary conditions often vary quite strongly with the temperature. The temperature fields are further influenced by movement of inductor and cooler, so the single parameters are functions of time as well. Moreover, a heated part is deformed during induction heating due to the thermal expansion, elastic and plastic deformation occurrence, i. e. the distance between inductor coil and a heated part is changed. Additionally, the dependence of mechanical properties on temperature must be taken into account.

\section{Governing equations for the electromagnetic field}

The governing equations for the electro-magnetic analysis can be derived from the classical Maxwell's equations [1-4]

$$
\begin{aligned}
& \operatorname{rot} \boldsymbol{H}=\boldsymbol{j}+\frac{\partial \boldsymbol{D}}{\partial t} \\
& \operatorname{rot} \boldsymbol{E}=-\frac{\partial \boldsymbol{B}}{\partial t}
\end{aligned}
$$




$$
\begin{aligned}
\operatorname{div} \boldsymbol{D} & =\rho_{e} \\
\operatorname{div} \boldsymbol{B} & =0 .
\end{aligned}
$$

The field vectors $\boldsymbol{D}$ and $\boldsymbol{E}$ and also $\boldsymbol{B}$ and $\boldsymbol{H}$ are related by material properties through the functions referred as the constitutive equations

$$
\begin{aligned}
& \boldsymbol{D}=\varepsilon \boldsymbol{E} \\
& \boldsymbol{B}=\mu \boldsymbol{H} \\
& \boldsymbol{j}=\sigma \boldsymbol{E} .
\end{aligned}
$$

Since magnetic flux density $\boldsymbol{B}$ satisfies a zero divergence condition, $\operatorname{div} \boldsymbol{B}=0$, the magnetic vector potential $\boldsymbol{A}$ can be defined by the relationship $[1,2]$

$$
\boldsymbol{B}=\operatorname{rot} \boldsymbol{A} .
$$

Then the Maxwell's equations (2)-(5) lead to following expressions of the diffusion equation for conductive (10) and non-conductive materials (11), respectively

$$
\begin{aligned}
& \Delta \boldsymbol{A}-\mu \varepsilon \frac{\partial^{2} \boldsymbol{A}}{\partial t^{2}}-\mu \sigma \frac{\partial \boldsymbol{A}}{\partial t}=0 \\
& \Delta \boldsymbol{A}-\mu \varepsilon \frac{\partial^{2} \boldsymbol{A}}{\partial t^{2}}=0
\end{aligned}
$$

For time harmonic electro-magnetic fields, the current density and magnetic vector potential vary with time according the relationships

$$
\begin{aligned}
& \boldsymbol{j}=\boldsymbol{j}_{0} e^{i \omega t} \\
& \boldsymbol{A}=\boldsymbol{A}_{0} e^{i \omega t}
\end{aligned}
$$

where $\omega$ is the angular frequency.

\section{Governing equations for the temperature field}

The temperature fields in solids are governed by the Fourier-Kirchhoff's heat diffusion equation [5]

$$
c \rho \frac{\partial T}{\partial t}=\operatorname{div}(\lambda \operatorname{grad} T)+q_{v}
$$

where the heat generated per unit time in a unit volume $q_{\mathrm{v}}$ depends on the Joule heat generation in a heated material due to the eddy currents rising in the process of induction heating.

Usually, three kinds of boundary conditions for heat diffusion equation (14) are used. The boundary condition of the first kind is determined by the given surface temperature as a function of position and time

$$
T=f_{1}(r, t) \quad \text { at the surface } S_{1}
$$


The boundary condition of the second kind expresses the surface conductive heat flux as a function of position and time

$$
\boldsymbol{q}=-\lambda \frac{\partial T}{\partial \boldsymbol{n}}=f_{2}(\boldsymbol{r}, t) \quad \text { at the surface } S_{2}
$$

where $\partial T / \partial \boldsymbol{n}$ denotes differentiation along the outward-drawn normal at the boundary surface $\mathrm{S}_{2}$. This condition is applied as well as at the adiabatic (insulated) surfaces or as a symmetry condition when the surface heat flux is zero.

Most frequently, a boundary condition of the third kind is used. According to this condition, the surface conduction heat flux is equal to the convection heat flux:

$$
-\lambda \frac{\partial T}{\partial \boldsymbol{n}}=h\left(T_{\mathrm{w}}-T_{\mathrm{f}}\right) \quad \text { at the surface } \mathrm{S}_{3}
$$

To apply this condition, it is necessary to know the surrounding temperature and the heat transfer coefficient. Usually, the combine heat transfer coefficient includes the influence of convection and radiation, so it is given by the sum of convection heat transfer coefficient $h_{\mathrm{C}}$ and radiation heat transfer coefficient $h_{\mathrm{R}}$.

$$
h=h_{\mathrm{C}}+h_{\mathrm{R}}=h_{\mathrm{C}}+\frac{\varepsilon_{12} \sigma_{0}\left(T_{\mathrm{w}}^{4}-T_{\mathrm{f}}^{4}\right)}{T_{\mathrm{w}}-T_{\mathrm{f}}}
$$

where $\varepsilon_{12}$ is the emissivity and $\sigma_{0}$ is the Stefan-Boltzmann's constant.

\section{Governing equations for the stress-strain fields}

Supposing the thermo-elastic material behavior, the stress-strain fields can be described by the vector equation [6]

$$
\Delta \boldsymbol{u}+\frac{1}{1-2 v} \operatorname{grad} \operatorname{div} \boldsymbol{u}-\frac{2(1+v)}{1-2 v} \alpha_{v} \operatorname{grad} T=\mathbf{0}
$$

The stress-strain dependence is given by the generalized Hooke's law in the form

$$
\sigma_{\mathrm{ij}}=C_{\mathrm{ijkl}} \varepsilon_{\mathrm{kl}}^{\mathrm{el}}=C_{\mathrm{ijkl}}\left(\varepsilon_{\mathrm{kl}}-\varepsilon_{\mathrm{kl}}^{\mathrm{th}}\right)
$$

in which the components of elastic strain $\varepsilon_{\mathrm{kl}}^{\mathrm{el}}$ and thermal strain $\varepsilon_{\mathrm{kl}}^{\mathrm{th}}$ are defined by relationships

$$
\begin{aligned}
& \varepsilon_{\mathrm{kl}}^{\mathrm{el}}=0.5\left(u_{\mathrm{kl}}+u_{\mathrm{kl}}\right), \\
& \varepsilon_{\mathrm{kl}}^{\text {th }}=\alpha_{\mathrm{v}} \Delta T .
\end{aligned}
$$




\section{Methodology of numerical solution}

Numerical analysis was performed by the general-purpose commercial finite element code ANSYS, Release 10.0 using the sequential field-coupling method [7-8]. The user defined subroutine was developed to control the field coupling [9-10].

\section{INDUCTION HEATING FOR THE PROCESS OF PISTON HARDENING}

\section{Process description and simulation model}

In the process of hardening of a power cylinder piston (Fig. 1) from the EN GJS700 ductile iron, the head of piston is heated using a copper water cooled inductor coil with the shape and two alternative dimensions according to Fig. 1. High frequency from $200 \mathrm{kHz}$ to $400 \mathrm{kHz}$ by the inductor power from $2.5 \mathrm{~kW}$ to $3 \mathrm{~kW}$ was suggested in order to heat material only in the piston surface layer. For the surface hardening of the head of piston, the heating to the austenitisation temperature during the time period of 17.5 seconds is required. Moreover, the temperature distribution in the top layer with the thickness of $2 \mathrm{~mm}$ should be quasi-uniform.

To solve this problem, the axisymmetric geometrical model (Fig. 2) for coupled electromagnetic, thermal and static analyses was prepared. A detail in Fig. 2 illustrates the generated finite element mesh considering the skin depth. The mesh density near the piston surface is quite high what corresponds to the exponential decrease in induced eddy currents and consequently in Joule heat generation in the direction from piston surface. Material properties of EN GJS700 ductile iron were considered to be temperature dependent. The phase transformations were included applying modified specific heat. Above the Curie temperature of $780{ }^{\circ} \mathrm{C}$, the material becomes nonmagnetic resulting in the decrease of heating rate. The heat extraction from the piston by mechanisms of convection and radiation were taken into account. The combined heat transfer coefficient was calculated in the dependence on the piston surface temperature. The initial temperature of the piston was supposed to be $20^{\circ} \mathrm{C}$. The current density in induction coil was computed using the electric analysis in ANSYS for given voltage on terminal connections. In Fig. 3, the applied current densities for alternative inductor geometries in the dependence on the distance from the centre of inductor coil are depicted. The diameter of inductor coil B is larger but the current density in this coil must be higher as its distance from the piston surface is greater. As a consequence, the electro-magnetic coupling between inductor and a heated material is weaker.

\section{Results of numerical simulation}

Induction heating is possible due to the existence of electro-magnetic field in the surroundings of induction coil and the phenomena of electro-magnetic induction and heat conduction in a heated material. The maximal intensity of magnetic field applying two alternative inductors in the time of 17.5 seconds are comparable (Fig. 4). However, the inductor coil $B$ provides more homogeneous magnetic field along the whole top surface of a heated piston. Nevertheless, magnetic field exhibits the lower intensity in the central part near the piston axis. 
Resulting temperature fields at the end of heating in the time of 17.5 seconds are illustrated in Fig. 5 for both considered inductor coils. By the use of inductor $A$, heating is localised particularly in the centre of a heated zone to the approximately one half of the piston perimeter (Fig. 5a). As it follows from Fig. 6, the central parts are overheated what can results in crack initiation and material failure during following water quenching [11-12]. On the other hand, in peripheral parts the temperatures even at the surface do not reach the austenitisation temperature. The temperature differences along the top surface are high exceeding $200{ }^{\circ} \mathrm{C}$.

Induction heating using the inductor B provides the more favourable temperature distribution for the surface hardening of a piston head (Fig. 5b). At the end of heating, material is warmed up above the austenitisation temperature through the required layer with the thickness of $2 \mathrm{~mm}$ (Fig. 6). In contrast to the material heating by inductor A, the minimal temperatures are in this case in the piston axis during almost whole heating process (Fig. 7). From the Fig. 7, the heating rates and the dwell time above the austenitisation temperature can be estimated as well.

\section{CONCLUSIONS}

Using the coupled electro-magnetic, thermal and static analyses, the process of high frequency induction heating for the hardening of the head of power cylinder piston was studied. Induction heating processes with exploitation of two geometrically different induction coils were compared based on the results of numerical simulation. The inductor coil A provides quite inhomogeneous temperature field in the heated zone with high temperatures in the central parts and low temperatures around the circumference of a piston head. The temperature distribution at the end of heating process using the inductor $B$ is more advantageous to required surface hardening but still not optimal. In this reason, the next work will be focused on the optimisation of induction heating including particularly the coil geometry and power.

\section{ACKNOWLEDGMENT}

The research has been supported by VEGA MS and SAV of the Slovak Republic within the project No. 1/0837/08 and 1/0721/08.

\section{REFERENCES}

[1] Haimbaugh, R. E., Practical Induction Heat Treating. ASM International, (2001).

[2] Novák, P., Základy elektrotepelnej techniky. Mercury-Smekal Košice, (2001).

[3] Langer, E., Teorie indukčního a dielektrického tepla, Academia Praha, (1979).

[4] http://www.ameritherm.com/aboutinduction.html, Induction Heating Basic Principles and Applications, [online, cit. 2006-10-03]

[5] Incropera, F. P., De Witt, D. P., Fundamentals of heat and mass transfer, J. Wiley and Sons New York, (1996).

[6] Kneshke, A., Používanie diferenciálnych rovníc v praxi. Alfa, Bratislava, (1968).

[7] Ansys Theoretical Manual, Release 10.0, SAS IP, Inc., (2005).

[8] Sadegiphour, K., Dopkin, J. A., Li, K., A computer aided finite element/ experimental analysis of induction heating process of steel. Computers in 
Industry, pp. 195 - 205, (1996).

[9] Behúlová, M., Mašek, B., Meyer, L.W, Static and dynamic induction heating experiment and numerical simulation. MP-Materialprüfung, Vol. 48, No. 5, pp. 217-224, (2006). ISSN 0025-5300

[10] Behúlová, M., Methodology of numerical solution of electro-magnetic and temperature fields by induction heating using the programm system ANSYS. In 20th International Conference of Heat Treatment. Praha, pp. $127-132$. (2004). ISBN 80-239-3561-5

[11] Kim, J.-D., Ji J.-K., Effect of super-rapid induction quenching on fatigue fracture behavior of spherical graphite cast iron FCD500Journal of Materials Processing Technology 176, pp. 19-23, (2006).

[12] Puškár, A., Hazlinger, M., Failures and fractures of components. EDIS, Žilina, (2000). ISBN: $80-7100-654-8$ 


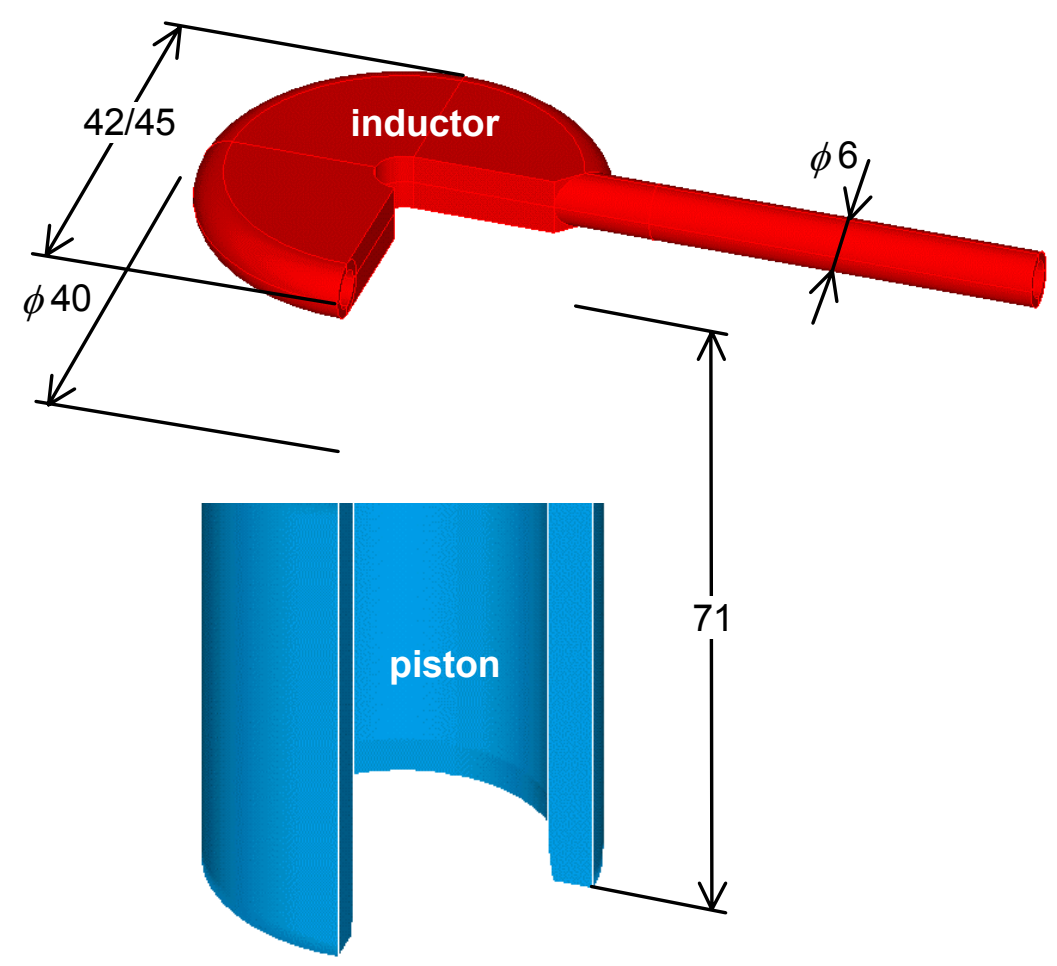

Fig. 1 Geometrical model of a power cylinder piston and induction coil with alternative dimensions

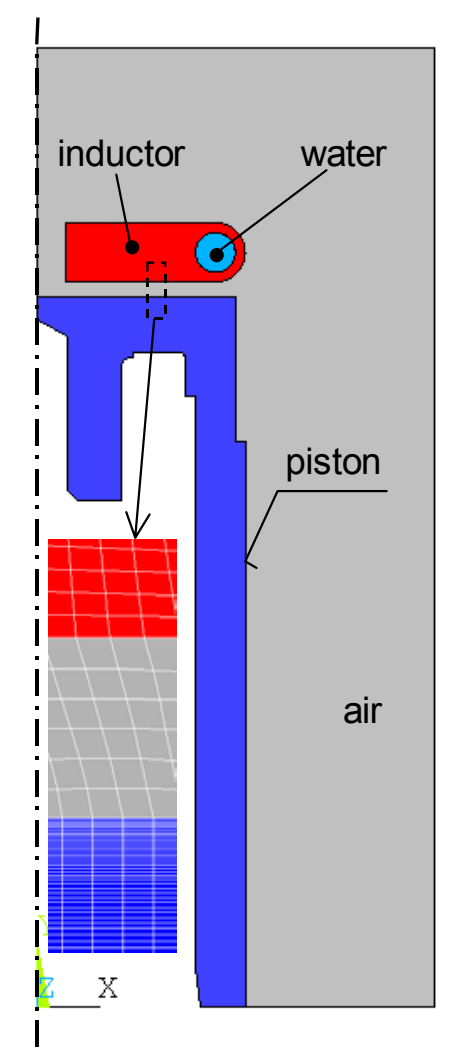

Fig. 2 Axisymmetric model for coupled analyses with the detail of generated finite element mesh 


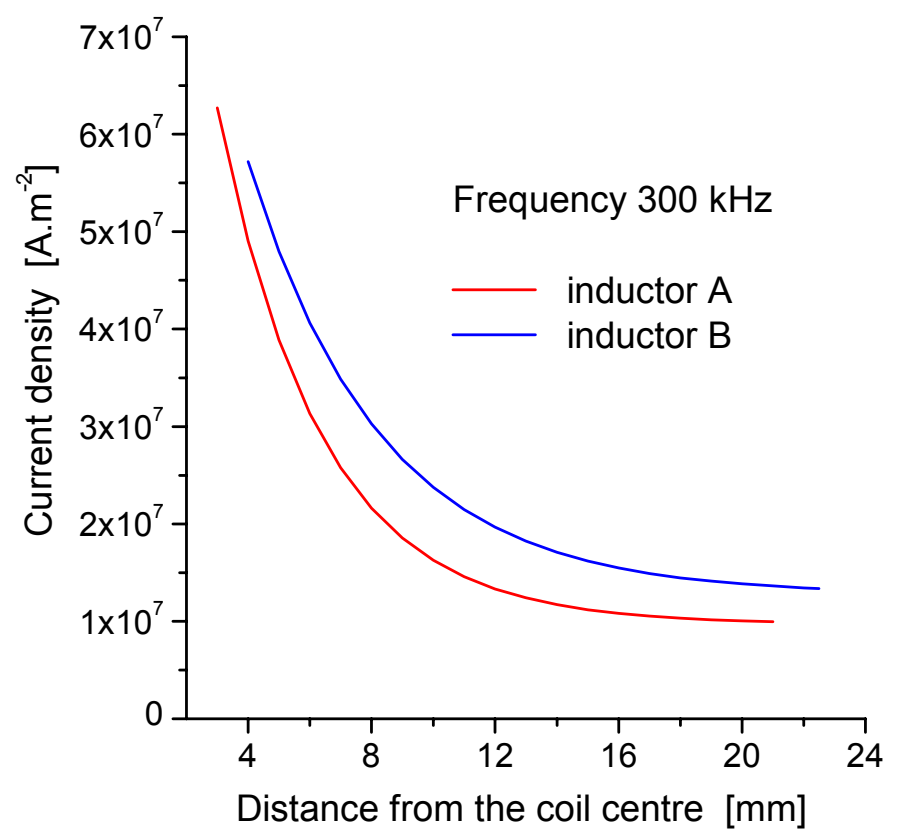

Fig. 3 Dependence of current density on the distance from the inductor coil centre
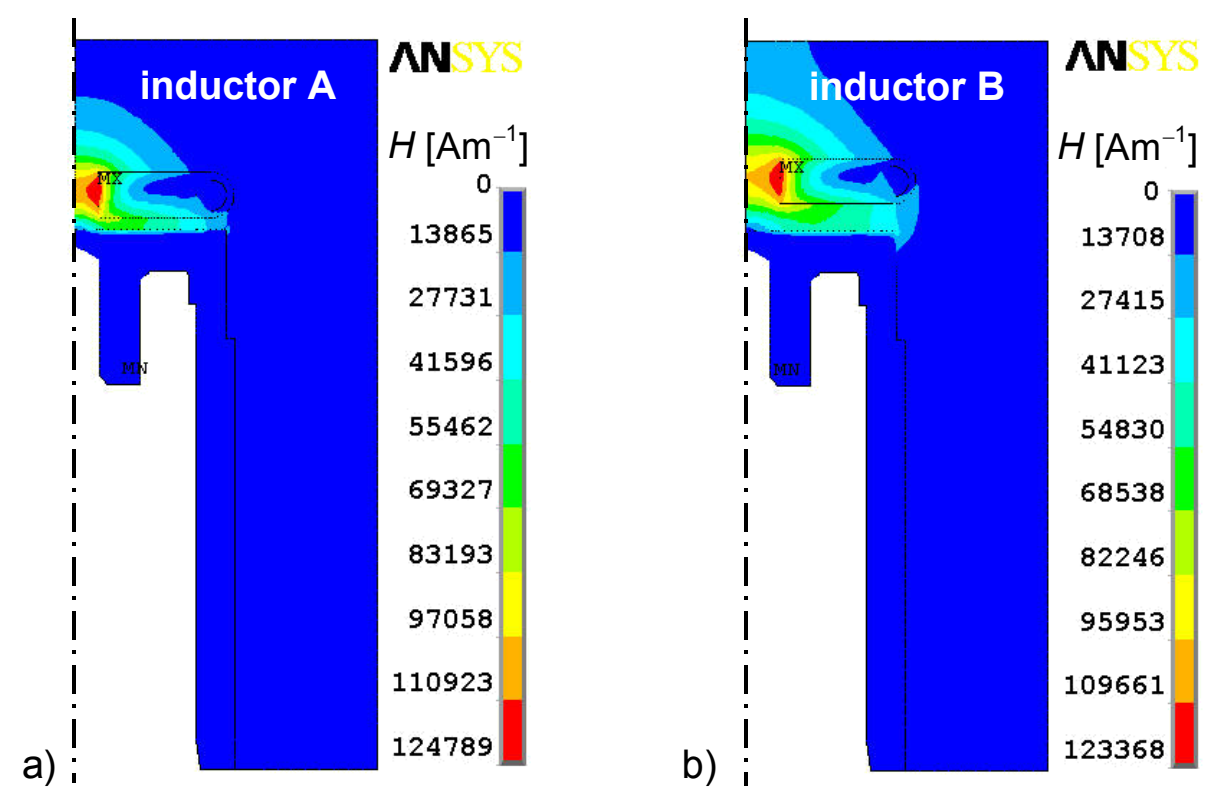

Fig. 4 Intensity of magnetic field in the time of $17.5 \mathrm{sec}$. using a) inductor $A$ and $b$ ) inductor $B$ 

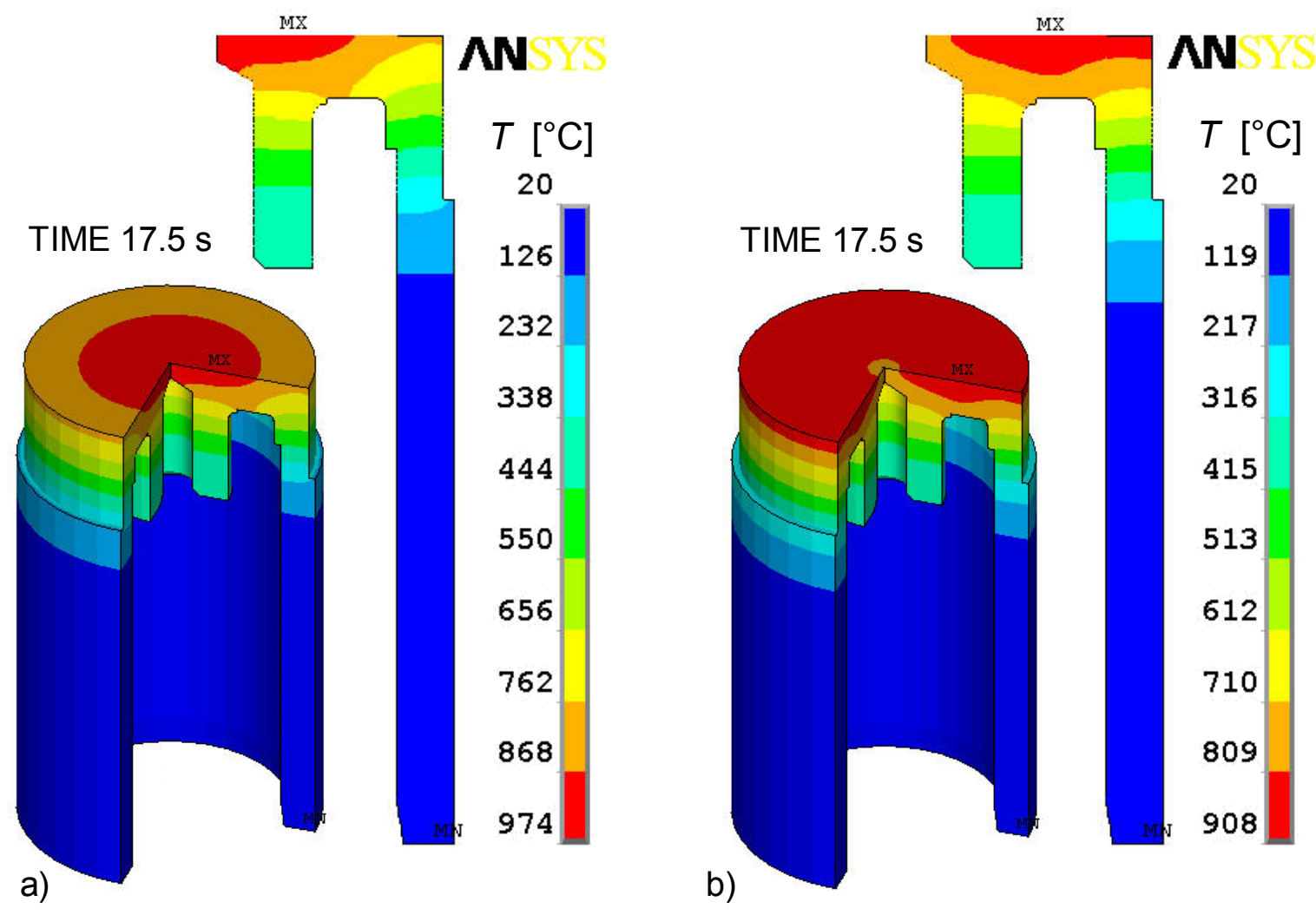

Fig. 5 Temperature distribution in a heated piston in the time of 17.5 seconds using a) inductor $A$ and $b$ ) inductor $B$ 


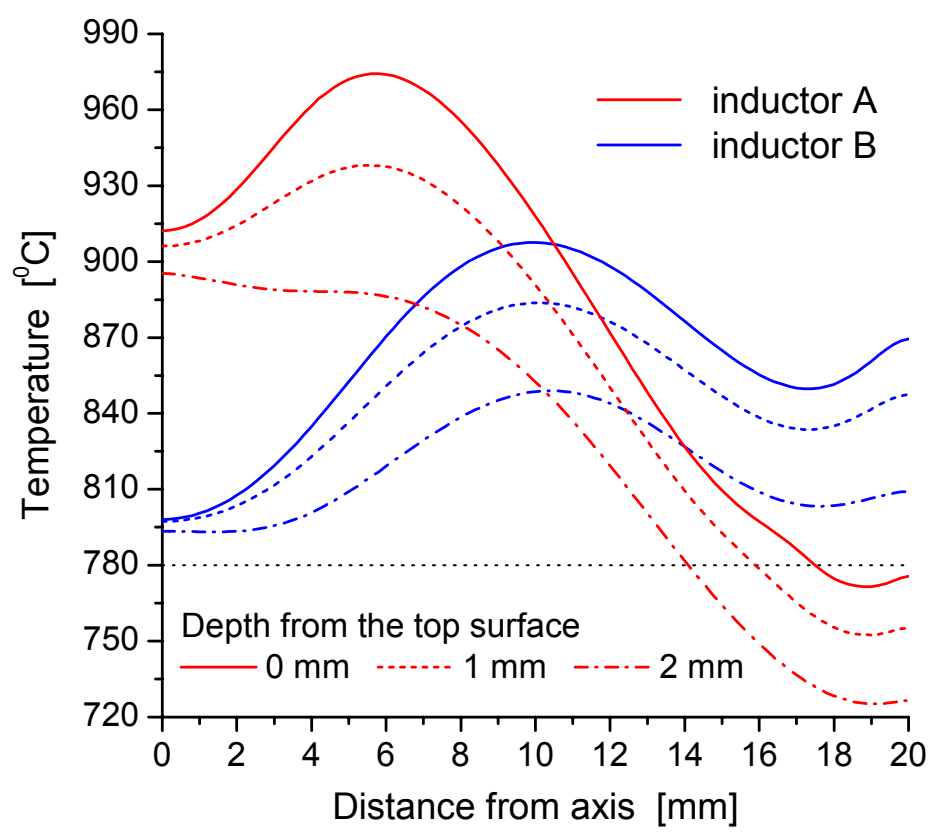

Fig. 6 Temperature distribution along the path from the piston axis at the top surface (solid lines), in the depth of $1 \mathrm{~mm}$ (dashed lines) and in the depth

of $2 \mathrm{~mm}$ (dashed-dot lines) at the end of induction
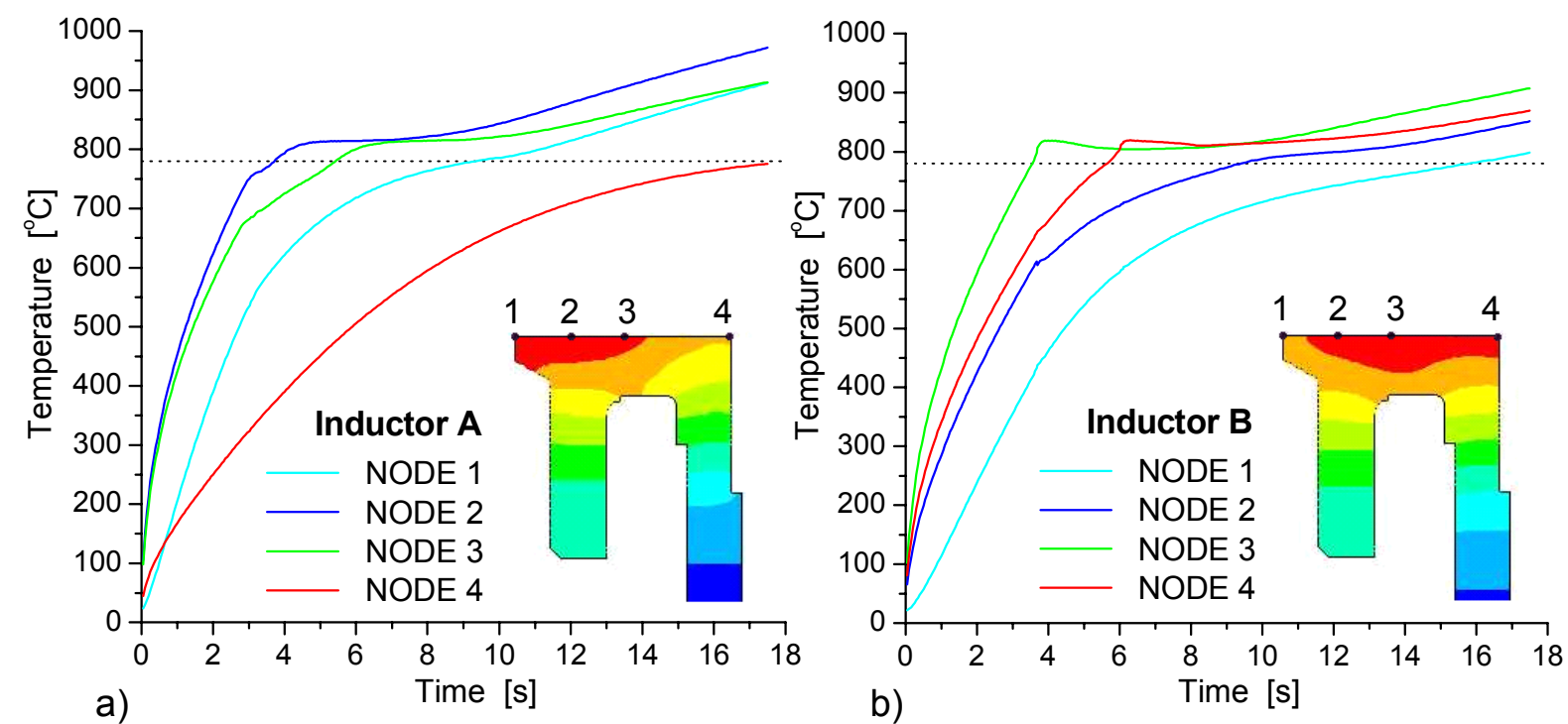

Fig. 7 Temperature histories in chosen nodes at the top surface of a piston during induction heating by $a$ ) inductor $A$ and $b$ ) inductor $B$ 